\title{
Integrasi Produksi - Distribusi pada Supply Chain dengan Pendekatan Hybrid Analitik - Simulasi
}

\author{
Annisa Kesy Garside ${ }^{1}$, R. Hadi Wahyuono², Tiananda Widyarini ${ }^{3}$
}

\begin{abstract}
Integrated production-distribution problem resolution using analytical model lacks of consideration of many uncertainties along supply chain line such as delays, queues, machine breakdown, vehicle malfunction, and environmental factor. By utilizing simulation as complex stochastic system modelling, this research aims to develop hybrid analytical-simulation approach to resolve integrated production-distribution model. Time capacity adjustment is required if production-distribution plan obtained from analytical model requires longer production and delivery time than available. The adjustment is using a procedure developed based on duration obtained from simulation model and is used to obtain adjusted time capacity. The implementation of hybrid method to resolve integrated production-distribution problem on two echelon supply chain with 2 factories and 5 Distribution Centre (DC) shows a feasible solution was obtained on the third iteration.
\end{abstract}

Keywords: Supply chain, production-distribution integration, analytical model, simulation model, stochastic.

\section{Pendahuluan}

Proses utama dalam sebuah Supply Chain (SC) adalah perencanaan produksi dan distribusi (Lee dan Sook, [7]). Adanya persaingan ketat dan pasar global telah mendorong perusahaan untuk mengurangi biaya operasi dan persediaan di sepanjang SC sehingga membawa hubungan yang lebih dekat diantara fungsi produksi dan distribusi (Chen, [3]). Sebagai akibatnya perusahaan harus beralih dari pengambilan keputusan yang bersifat terpisah menjadi menjadi terkoordinasi dan terintegrasi diantara fungsi-fungsi yang ada (Thomas dan Paul, [10]).

Literatur-literatur Supply Chain (SC) menunjukkan bahwa optimasi dan simulasi perencanaan produksi-distribusi merupakan area yang sering diteliti dalam dekade-dekade terakhir ini (Fahimnia et al., [4]). Linear Programming (LP) dan Mixed Integer Programming (MIP) banyak digunakan untuk membuat model analitik pada problem integrasi produksi distribusi. Namun model analitik memiliki kelemahan karena mengasumsikan waktu produksi dan pengiriman bersifat deterministik, sehingga kurang mampu mengakomodasi ketidakpastian yang ada di dalam SC. diantaranya delay, antrian, kerusakan

\footnotetext{
1 Fakultas Teknologi Industri, Jurusan Teknik Industri. Universitas Muhammadiyah Malang, Л. Dinoyo, Malang 40132. Email: annisa_garside@yahoo.com.

2,3 Fakultas Teknologi Industri, Jurusan Teknik Industri, Institut Teknologi Sepuluh Nopember Surabaya, Kampus Keputih Sukolilo, Surabaya 60111
}

Diterima 16 November 2010; revis1 17 April 2011; revisi2 3 Mei 2011; Diterima untuk publikasi 10 Mei 2011. mesin, kerusakan kendaraan, dan faktor lingkungan (cuaca, macet). Simulasi telah terbukti sebagai alat evaluasi performansi yang efektif dan alat pemodelan untuk sistem stokastik di dunia nyata yang sangat kompleks. Alfieri dan Brandimarte [1] dan Wang dan Soemon [11] telah menggunakan simulasi untuk memvisualisasikan perencanaan produksi-distribusi yang bisa berdaptasi dengan berbagai kebijakan persediaan, dan Lim et al., [8] pada kebijakan replenishment di pabrik dan Distribution Center (DC). Lee dan Sook [7] dan Garside [5] menggunakan model simulasi yang telah mempertimbangkan faktor stokastik SC untuk memvalidasi solusi model analitik yang telah dikembangkan sebelumnya. Kedua model simulasi tersebut menggambarkan network supply chain yang berbeda namun hasil simulasi menunjukkan solusi model analitik menjadi tidak layak karena total waktu simulasi melebihi kapasitas waktu produksi yang tersedia, sehingga diperlukan penyesuaian atau penambahan kapasitas agar solusi model analitik menjadi layak pada saat diimplementasikan.

Berdasarkan kelebihan model simulasi dalam mengakomodasi karakteristik stokastik dan kelebihan model analitik dalam menghasilkan solusi yang optimal, maka penelitian ini bertujuan mengembangkan pendekatan hybrid analitik-simulasi untuk menyelesaikan problem integrasi produksi-distribusi pada sebuah SC terdiri dari banyak pabrik yang akan mensuplai berbagai jenis produk ke banyak DC. Penggabungan kelebihan kedua model tersebut akan menghasilkan solusi rencana produksi dan distribusi yang meminimalkan biaya produksi dan distribusi dan layak diimplementasikan di realita. 


\section{Metode Penelitian}

Penelitian ini mengasumsikan bahwa hubungan antara variabel-variabel dalam fungsi tujuan dan pembatas adalah linear. Selain itu beberapa parameter model dipertimbangkan bernilai stokastik. dikarenakan mengakomodasi ketidakpastian yang berlangsung dalam supply chain. Ketidakpastian berupa delay, variasi kecepatan kendaraan, kerusakan mesin dan kerusakan kendaraan akan mempengaruhi nilai parameter waktu produksi, waktu perjalanan, kapasitas waktu produksi dan kapasitas waktu kendaraan menjadi acak atau berdistribusi peluang tertentu. Berdasarkan penjelasan tersebut maka model yang akan dikembangkan masuk dalam kategori Model Linear Stokastik. Sumarwan et al. [9] dan Chairunisah [2] menyatakan penyelesaian model stokastik seringkali dibawa ke deterministik agar dapat dipecahkan, sehingga dalam penelitian ini diputuskan untuk menggunakan model linear deterministik agar penyelesaian masalah lebih mudah dilakukan dan selanjutnya akan digunakan simulasi untuk mengakomodasi ketidakpastian berupa variasi waktu produksi, kecepatan kendaraan, kerusakan mesin dan kerusakan kendaraan.

Metode Penelitian akan menjelaskan tahapan-tahapan penelitian yang dilakukan yaitu: (1) formulasi model analitik (matematika), (2) perancangan model simulasi, dan (3) pengembangan prosedur hybrid analitik-simulasi.

\section{Formulasi Model Analitik}

Garside [6] mengembangkan model integrasi produksi-distribusi untuk menentukan jenis produk yang harus diproduksi, jumlah produksi, kuantitas dan jumlah pengiriman dari masing-masing pabrik ke masing-masing DC, serta persediaan di pabrik dan DC. Persediaan tersebut berfungsi sebagai safety stock sehingga pabrik dan DC dapat mengantisipasi ketidakpastian permintaan dan pasokan yang berlangsung dalam supply chain dan anticipation/seasonal stock dimana pabrik dan DC menggunakan persediaan yang dibuat pada periode permintaan rendah untuk memenuhi permintaan pada musim puncak. Model ini memodifikasi model yang telah dikembangkan sebelumnya dengan mengijinkan permintaan tidak terpenuhi jika tidak menggunakan alokasi persediaan dan pabrik akan kehilangan biaya kesempatan untuk memenuhi permintaan tersebut.

Variabel keputusan dalam model integrasi produksidistribusi dinyatakan sebagai berikut:

$P_{i, k}(t)$ : kuantitas produk ke- $k$ yang diproduksi oleh pabrik ke- $i$ selama periode ke- $t$ (unit) $x_{i, k}(t)$ : bernilai 1 jika pabrik ke-i harus memproduksi produk ke- $k$ pada periode ke- $t$ dan bernilai 0 jika sebaliknya

$N I_{i, k}(t)$ : persediaan bersih (net inventory) untuk produk ke- $k$ di pabrik ke- $i$ pada akhir periode akhir ke- $t$ (unit)

$G I_{i, k}(t)$ : persediaan kotor (gross inventory) untuk produk ke- $k$ di pabrik ke- $i$ pada akhir periode akhir ke- $t$ (unit)

$S_{i, k}(t) \quad$ : jumlah permintaan yang tidak terpenuhi untuk produk ke- $k$ di pabrik ke- $i$ pada akhir periode ke- $t$ (unit) jika tidak menggunakan alokasi persediaan bagi konsumen

$y_{i, j}^{v}(t)$ : jumlah pengiriman langsung dari pabrik ke- $i$ menuju DC ke-j oleh kendaraan $v$ dalam periode ke- $t$

$q_{i, j, k}^{v}(t)$ : kuantitas produk ke- $k$ yang dikirimkan dari pabrik ke- $i$ menuju DC ke-j oleh kendaraan $v$ dalam periode ke- $t$ (unit)

$I_{j, k}(t) \quad$ : persediaan produk ke- $k$ di DC ke-j pada akhir periode ke-t (unit)

Notasi parameter yang digunakan adalah:

I : Himpunan pabrik

$J \quad$ : Himpunan DC

$T \quad$ : Himpunan periode waktu

$K \quad$ : Himpunan produk

$V(t) \quad$ : Himpunan kendaraan yang dimiliki oleh pabrik $i$

$a_{i, k}(t)$ : Biaya produksi satu unit produk ke- $k$ di pabrik $i$ pada periode ke- $t$

$s_{i, k}(t)$ : Biaya set up produk ke- $k$ di pabrik ke- $i$ pada periode ke- $t$

$B_{i}(t) \quad$ : Kapasitas waktu produksi di pabrik ke- $i$ selama periode ke- $t$ (jam)

$P_{i, k^{\max }}:$ Kapasitas produksi maksimum untuk membuat produk ke- $k$ pada pabrik $i$

$t_{i, k} \quad$ : Waktu yang dibutuhkan untuk membuat 1 unit produk ke- $k$ di pabrik ke- $i$

$h_{i, k}(t)$ : Biaya simpan per unit produk ke- $k$ di pabrik ke-i selama periode ke- $t$

$\pi_{i, k}(t)$ : Biaya kesempatan yang hilang per unit produk ke- $k$ di pabrik ke- $i$ selama periode ke-t untuk memenuhi permintaan langsung konsumen

$h_{j, k}(t)$ : Biaya simpan per unit produk ke- $k$ di DC ke-j selama periode $t$

$W_{i} \quad$ : Kapasitas tempat penyimpanan di pabrik ke-i (dalam satuan volume)

$I_{i, k} \min \quad$ : Persediaan akhir minimum produk ke- $k$ di pabrik ke-i yang dialokasikan untuk permintaan langsung ke konsumen.

$W_{j} \quad$ : Kapasitas tempat penyimpanan di DC ke-j (dalam satuan volume)

$I_{j, k} \min \quad$ : Persediaan akhir minimum produk ke- $k$ di DC ke-j 
$c_{v} \quad$ : Biaya pengiriman untuk kendaraan $v$ (per jam)

$v_{k} \quad:$ volume produk ke- $k$ tiap satu unit

$C_{v} \quad:$ Kapasitas angkut maksimum untuk kendaraan $v$ (dalam satuan volume)

$T_{v}(t) \quad$ : Kapasitas waktu untuk kendaraan $v$ selama periode $t$

$t_{i, j}^{V} \quad$ : Waktu perjalanan dari pabrik $i$ ke DC $j$ dan kembali lagi ke pabrik $i$ dengan menggunakan kendaraan $v$ (dalam satuan jam)

$D_{j, k}(t)$ : Permintaan untuk produk ke- $k$ di DC ke-j pada periode ke- $t$

Formulasi model analitik menggunakan Mixed Integer Programming (MIP) sebagai berikut:

Min

$\sum_{t \in T} \sum_{i \in I} \sum_{k \in K} s_{i, k}(t) \cdot x_{i, k}(t)+$

$\sum_{t \in T} \sum_{i \in I} \sum_{k \in K} a_{i, k}(t) \cdot P_{i, k}(t)+$

$\sum_{t \in T} \sum_{i \in I} \sum_{k \in K} h_{i, k}(t) \cdot I_{i, k}(t)+$

$\sum_{t \in T} \sum_{t \in T} \sum_{i \in I} \sum_{k \in K} \pi_{i, k}(t) . S_{i, k}(t)+$

$\sum_{t \in T} \sum_{i \in I} \sum_{k \in K} h_{j, k}(t) . I_{j, k}(t)+$

$\sum_{t \in T} \sum_{i \in I} \sum_{k \in K} c_{v} \cdot t_{i, j}^{v} \cdot y_{i, j}^{v}(t)$

Fungsi Pembatas

$$
\begin{aligned}
& \sum_{k \in K} t_{i, k} P_{i, k}(t) \leq B_{i}(t), \forall_{i} \in I, t \in T \\
& P_{i, k}(t) \leq P_{i, k}^{\max } \cdot x_{i, k}(t), \forall_{i} \in I, k \in K, t \in T \\
& N I_{i, k}(t)=N I_{i, k}(t-1)+P_{i, k}(t)- \\
& \sum_{j \in J} \sum_{v \in V(i)} q_{i, j, k}^{v}(t), \forall_{i} \in I, k \in K, t \in T \\
& N I_{i, k}(t)=G I_{i, k}(t)-S_{i, k}(t), \forall_{i} \in I, k \in K, t \in T \\
& I_{j, k}(t)=I_{j, k}(t-1)+\sum_{i \in I} \sum_{v \in V(i)} q_{i, j, k}^{v}(t)- \\
& D_{j, k}(t), \forall_{j} \in J, k \in K, t \in T \\
& G I_{i, k}(t) \geq I_{i, k}^{\min }, \forall_{i} \in I, k \in K, t \in T \\
& I_{j, k}(t) \geq I_{j, k}^{\min }, \forall_{j} \in J, k \in K, t \in T \\
& \sum_{k \in K} N I_{i, k}(t) \cdot v_{k} \leq W_{i,} \forall_{i} \in I, t \in T \\
& \sum_{k \in K} I_{j, k}(t) \cdot v_{k} \leq W_{j}, \forall_{j} \in J, t \in T \\
& \sum_{k \in K} q_{i, j, k}^{v}(t) \cdot v_{k} \leq C_{v} \cdot y_{i, j}^{v}(t), \forall_{i} \in I, v \in V(i) \text {, } \\
& j \in J, t \in T \\
& \sum_{j \in J} t_{i, j}^{v} \cdot y_{i, j}^{v}(t) \leq T_{v}(t), \forall_{i} \in I, v \in V(i), t \in T \\
& y_{i, j}^{v}(t) \geq 0 \text { dan bilangan integer } \\
& x_{i, k}(t) \in\{0,1\} \\
& P_{i, k}(t) \geq 0, N I_{i, k}(t) \geq 0, G I_{i, k}(t) \geq 0 \text {, } \\
& S_{i, k}(t) \geq 0, q_{i, j, k}^{v}(t) \geq 0, I_{j, k}(t) \geq 0
\end{aligned}
$$

Model ini akan meminimasi total biaya dari biaya set up produksi, biaya produksi variabel, biaya simpan di pabrik, biaya kesempatan yang hilang di pabrik, biaya simpan di DC, dan biaya pengiriman secara reguler. Batasan 1 dan 2 menjamin jumlah produksi tiap produk tidak melebihi kapasitas waktu produksi dan kapasitas produksi di masingmasing pabrik. Batasan 3 dan 5 merupakan persamaan keseimbangan persediaan tiap produk di masing-masing pabrik dan DC. Batasan 4 adalah persamaan untuk menghitung persediaan bersih untuk tiap produk di tiap pabrik, yang diperoleh dari selisih antara persediaan kotor dengan jumlah permintaan yang tidak terpenuhi jika tidak menggunakan alokasi persediaan. Batasan 6 menjamin persediaan kotor (gross inventory) untuk tiap produk lebih besar dari persediaan minimum di tiap pabrik. Sedangkan Batasan 7 menjamin jumlah persediaan tiap produk lebih besar dari persediaan minimum di masing-masing DC. Batasan 8 dan 9 memastikan jumlah persediaan tidak melebihi kapasitas tempat penyimpanan di masing-masing pabrik dan DC. Batasan 10 menjamin kuantitas pengiriman seluruh produk tidak melebihi kapasitas angkut kendaraan yang dimiliki masing-masing pabrik. Sedangkan batasan 11 menjamin jumlah pengiriman langsung dari pabrik ke DC tidak melebihi kapasitas waktu pengiriman reguler yang dimiliki tiap kendaraan. Batasan 12 memberlakukan non negatif dan bilangan integer untuk variabel keputusan $y_{i, j}^{v}(t)$. Batasan 13 memberlakukan bilangan biner untuk variabel keputusan $x_{i, k}(t)$. Batasan 14 memberlakukan bilangan non negatif untuk variabel keputusan selain kedua variabel keputusan yang sudah dinyatakan pada batasan 12 dan 13 .

\section{Perancangan Model Simulasi}

Perancangan model simulasi menggunakan software ARENA dan VBA yang terintegrasi dalam software tersebut. Data-data yang diinputkan pada model simulasi meliputi: (1) Rencana produksi - distribusi yang dihasilkan dari model analitik. Untuk mempermudah proses input dikembangkan Worksheet Excel yang terintegrasi dengan VBA ARENA sehingga setiap perubahan secara otomatis akan merubah model simulasi. (2) Waktu produksi tiap produk di tiap pabrik. (3) Jarak dari tiap pabrik ke tiap DC. (4) Kecepatan kendaraan. (5) Waktu antar kerusakan dan perbaikan mesin di masing-masing pabrik. (6) Waktu antar kerusakan dan waktu perbaikan masing-masing kendaraan.

Gambar 1 menunjukkan flow chart model simulasi aktivitas produksi dan distribusi pada sebuah supply chain. Model simulasi untuk aktivitas produksi pada pabrik terdiri dari proses kedatangan produk setengah jadi dari line production yang lain, proses produksi, penentuan jumlah produk yang akan dikirim, penentuan kendaraan dan distribution center yang akan dituju. Produk yang telah digolongkan berdasarkan ukuran pengiriman, tujuan, dan kendaraan, selanjutnya dikirimkan dengan menggunakan kendaraan menuju distribution center. Dalam penelitian ini, sub model travel dan distribution center merupakan model simulasi untuk aktivitas distribusi yang berlangsung dari pabrik ke DC. 


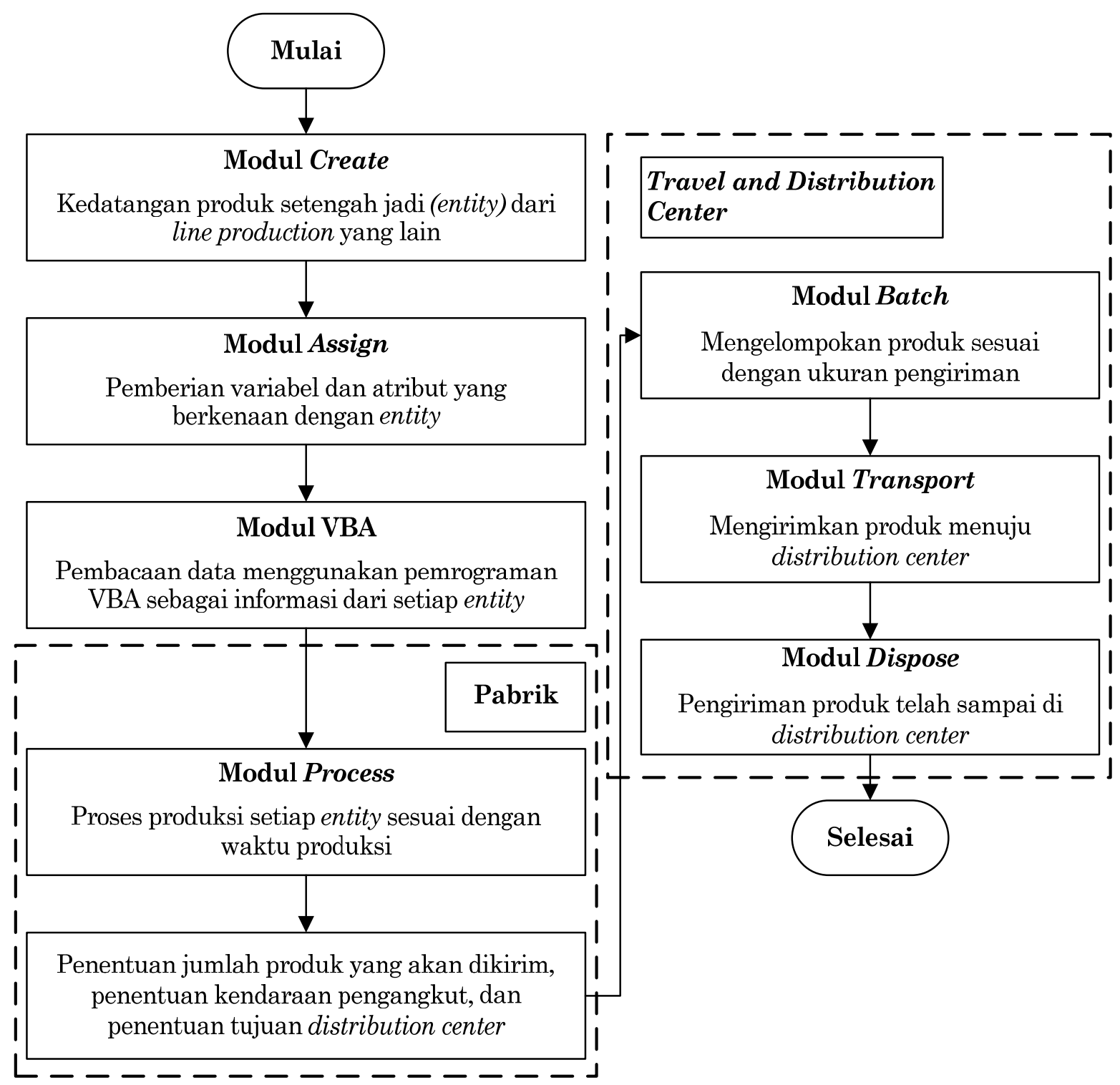

Gambar 1. Flow chart model simulasi dengan VBA ARENA

\section{Pengembangan Prosedur Hybrid Analitik-} Simulasi

Prosedur hybrid analitik-simulasi yang dikembangkan mengacu pada prosedur yang diusulkan Lee and Sook [7] dengan perbedaan terletak pada prosedur penyesuaian kapasitasnya. Penyesuaian tersebut berdasarkan waktu dari model simulasi sehingga diperoleh kapasitas waktu yang disesuaikan (adjusting capacity).

Gambar 2 menunjukkan penyesuaian kapasitas yang dikembangkan dengan mengikuti langkahlangkah sebagai berikut:

Step 1. Kapasitas waktu telah disesuaikan sehingga diperoleh kapasitas waktu produksi di tiap pabrik dan waktu pengiriman masingmasing kendaraan untuk iterasi ke-i.
Step 2. Menentukan rencana produksi dan distribusi di masing-masing pabrik pada tiap periode dengan menggunakan model analitik berdasarkan kapasitas dari step 1 .

Step 3. Menjalankan model simulasi berdasarkan solusi dari step 2 dengan replikasi sebanyak 15 kali.

Step 4. Menghitung selang kepercayaan rata-rata waktu simulasi di masing-masing pabrik pada tiap periode dengan menggunakan uji $t$ pada tingkat kepercayaan $95 \%$.

Step 5. Menetapkan batas atas/nilai maksimum dari selang kepercayaan sebagai waktu simulasi di pabrik ke-p pada periode k- $t$.

Step 6. Jika waktu simulasi pada masing-masing pabrik pada tiap periode tidak melebihi kapasitas waktu yang tersedia maka berhenti/stop. Jika masih ada salah satu yang belum memenuhi, lanjutkan step 7 . 


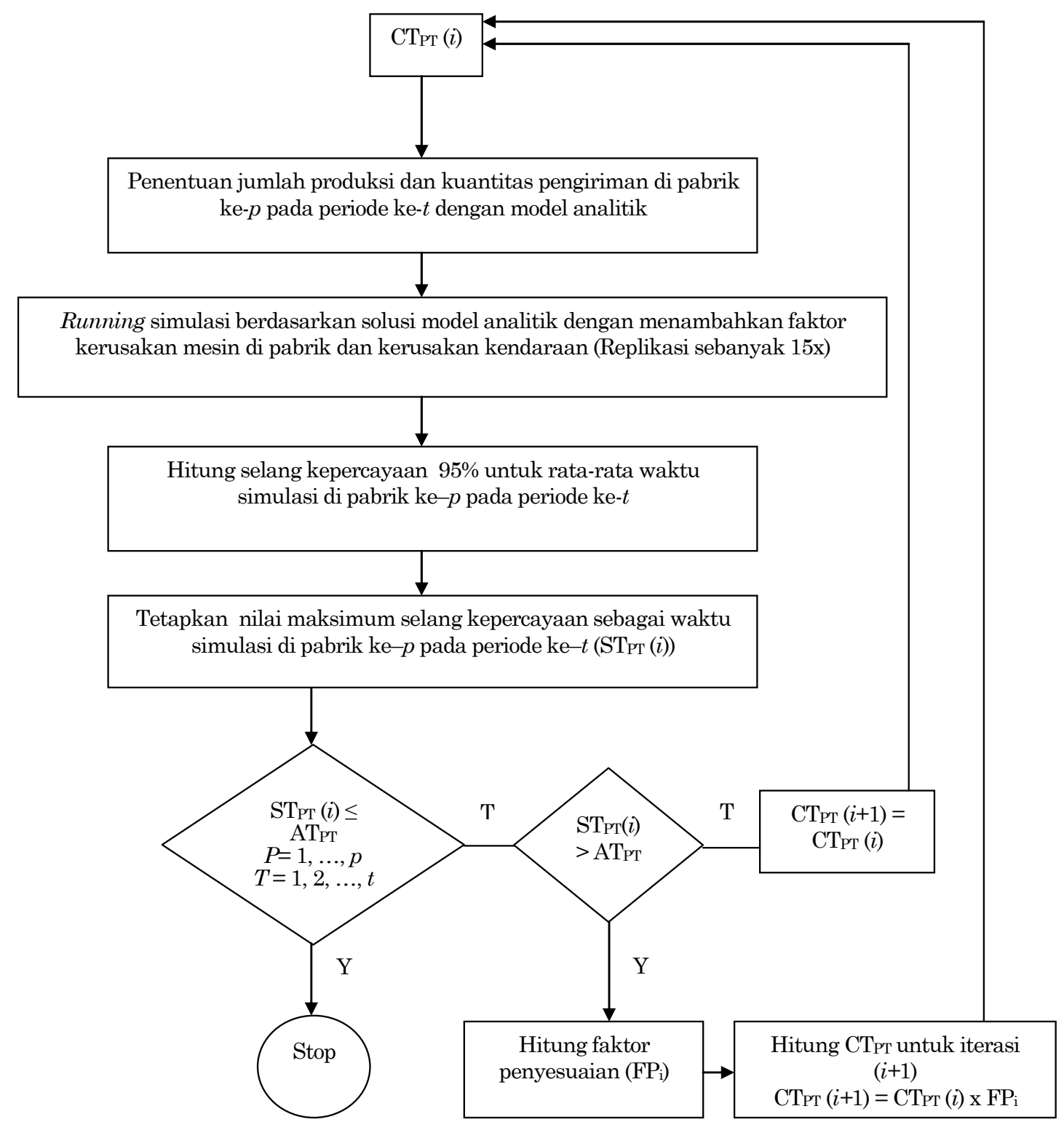

Gambar 2. Penyesuaian kapasitas waktu dalam prosedur hybrid analitik-simulasi

Step 7. Cek waktu simulasi pada masing-masing pabrik pada tiap periode. Jika waktu simulasinya sudah lebih kecil dari waktu tersedia maka lanjut ke step 8. Jika tidak, lanjutkan ke step 9 dan 10.

Step 8. Tetapkan kapasitas waktu yang telah disesuaikan untuk iterasi ke- $i+1$ sama dengan iterasi ke- $i$.

Step 9. Hitung faktor penyesuaian kapasitas waktu untuk pabrik ke-p pada periode ke- $t$ dengan menggunakan persamaan:

$F P_{i}=\frac{C T_{P T}(i)}{S T_{P T}(i)}$

Step 10.Tetapkan kapasitas waktu yang telah disesuaikan di pabrik ke- $p$ pada periode ke- $t$ untuk iterasi ke-i+1 dengan menggunakan persamaan:

$C T_{P T}(i+1)=C T_{P T}(i) \times F P_{i}$

\section{Hasil dan Pembahasan}

Pada bagian ini diberikan contoh numerik sebagai gambaran implementasi pendekatan hybrid analitik -simulasi. Prosedur hybrid analitik-simulasi digunakan untuk menyelesaikan sebuah problem integrasi produksi-distribusi yang berlangsung pada two echelon supply chain yang terdiri dari 2 pabrik dan 5 DC. Masing-masing pabrik dapat memproduksi 2 produk dan mengirimkannya secara langsung ke DC dengan menggunakan 2 kendaraan yang dimiliki tiap pabrik. Horison perencanaan yang dipertimbangkan adalah 3 periode dimana masing-masing memiliki waktu tersedia sebesar 48 jam.

Sesuai dengan prosedur yang dijelaskan pada Gambar 2 maka langkah pertama adalah mendapatkan rencana produksi-distribusi dengan menggunakan model analitik yang telah dikembangkan. 
Tabel 1. Rencana produksi dan persediaan pabrik dari solusi model analitik

\begin{tabular}{|c|c|c|c|c|c|c|c|c|}
\hline \multirow{2}{*}{ Pabrik } & \multirow{2}{*}{ Produk } & \multirow{2}{*}{ Periode } & \multicolumn{2}{|c|}{ Iterasi 1} & \multicolumn{2}{|c|}{ Iterasi 2} & \multicolumn{2}{|c|}{ Iterasi 3} \\
\hline & & & Produksi & Prsediaan & Produksi & Prsediaan & Produksi & Prsediaan \\
\hline \multirow{5}{*}{$\mathrm{P} 1$} & 1 & 1 & 2251 & 333 & 1996 & 333 & 1641 & 333 \\
\hline & & 2 & 2265 & 333 & 2300 & 336 & 2312 & 332 \\
\hline & & 3 & 3522 & 333 & 3169 & 310 & 2538 & 333 \\
\hline & 2 & 1 & 4248 & 325 & 4205 & 325 & 4354 & 325 \\
\hline & & 2 & 4145 & 325 & 3755 & 702 & 3343 & 421 \\
\hline \multirow{7}{*}{$\mathrm{P} 2$} & & 3 & 1985 & 325 & 2368 & 324 & 2492 & 325 \\
\hline & 1 & 1 & 2539 & 333 & 3089 & 333 & 3089 & 333 \\
\hline & & 2 & - & 333 & - & 333 & - & 333 \\
\hline & & 3 & - & 333 & - & 333 & 997 & 333 \\
\hline & 2 & 1 & 1623 & 325 & 1672 & 325 & 1509 & 325 \\
\hline & & 2 & - & 325 & - & 325 & - & 325 \\
\hline & & 3 & - & 325 & - & 325 & 303 & 325 \\
\hline
\end{tabular}

Tabel 2. Rencana pengiriman dan persediaan DC dari solusi model analitik

\begin{tabular}{|c|c|c|c|c|c|c|c|c|c|c|c|c|c|c|c|}
\hline \multirow[t]{2}{*}{$\mathrm{DC}$} & \multirow[t]{2}{*}{ Prduk } & \multirow[t]{2}{*}{ Priode } & \multirow{2}{*}{$\begin{array}{l}\text { Permin- } \\
\text { taan }\end{array}$} & \multicolumn{9}{|c|}{$\begin{array}{l}\text { Kuantitas Pengiriman dari Pabrik (P) dengan kendaraan (V) } \\
\text { di iterasi ke- }\end{array}$} & \multicolumn{3}{|c|}{$\begin{array}{l}\text { Persediaan DC di tiap } \\
\text { iterasi }\end{array}$} \\
\hline & & & & & 1 & & & 2 & & & 3 & & 1 & 2 & 3 \\
\hline \multirow{6}{*}{1} & \multirow[t]{2}{*}{1} & 1 & 491 & 963 & P2 & V3 & 963 & $\mathrm{P} 2$ & V3 & 824 & $\mathrm{P} 1$ & V1 & 472 & 472 & 333 \\
\hline & & 2 & 975 & 848 & $\mathrm{P} 1$ & V1 & 1175 & P1 & V1 & 975 & $\mathrm{P} 1$ & V1 & 345 & 672 & 333 \\
\hline & \multirow{4}{*}{2} & 3 & 997 & 985 & $\mathrm{P} 1$ & V1 & 658 & P1 & V1 & 997 & $\mathrm{P} 2$ & V4 & 333 & 333 & 333 \\
\hline & & 1 & 398 & 663 & P2 & V3 & 663 & P2 & V3 & 663 & $\mathrm{P} 1$ & V1 & 265 & 265 & 265 \\
\hline & & 2 & 795 & 1122 & $\mathrm{P} 1$ & V1 & 795 & P1 & V1 & 819 & $\mathrm{P} 1$ & V1 & 592 & 265 & 289 \\
\hline & & 3 & 327 & & $\mathrm{P} 1$ & V1 & 327 & P1 & V1 & 303 & P2 & V4 & 265 & 265 & 265 \\
\hline \multirow{5}{*}{2} & \multirow[t]{3}{*}{1} & 1 & 134 & 586 & $\mathrm{P} 1$ & V1 & 291 & $\mathrm{P} 1$ & V1 & 484 & $\mathrm{P} 1$ & V1 & 452 & 157 & 350 \\
\hline & & 2 & 343 & 43 & $\mathrm{P} 1$ & V1 & 338 & P1 & V1 & 145 & $\mathrm{P} 1$ & V1 & 152 & 152 & 152 \\
\hline & & 3 & 455 & 455 & $\mathrm{P} 1$ & V1 & 455 & P1 & V1 & 455 & $\mathrm{P} 1$ & V1 & 152 & 152 & 152 \\
\hline & \multirow[t]{3}{*}{2} & 1 & 975 & 1332 & $\mathrm{P} 1$ & V1 & 1627 & $\mathrm{P} 1$ & $\mathrm{~V} 1$ & 1434 & $\mathrm{P} 1$ & V1 & 357 & 652 & 459 \\
\hline & & 2 & 974 & 942 & $\mathrm{P} 1$ & V1 & 647 & $\mathrm{P} 1$ & $\mathrm{~V} 1$ & 840 & $\mathrm{P} 1$ & V1 & 325 & 325 & 325 \\
\hline \multirow{7}{*}{3} & & 3 & 363 & 363 & $\mathrm{P} 1$ & V1 & 362 & $\mathrm{P} 1$ & V1 & 363 & $\mathrm{P} 1$ & V1 & 325 & 325 & 325 \\
\hline & \multirow[t]{3}{*}{1} & 1 & 603 & 937 & $\mathrm{P} 1$ & V1 & 1372 & $\mathrm{P} 1$ & V1 & 937 & $\mathrm{P} 2$ & V4 & 334 & 769 & 334 \\
\hline & & 2 & 568 & 435 & $\mathrm{P} 1$ & V1 & - & $\mathrm{P} 1$ & $\mathrm{~V} 1$ & 435 & $\mathrm{P} 1$ & $\mathrm{~V} 1$ & 201 & 201 & 201 \\
\hline & & 3 & 506 & 506 & $\mathrm{P} 1$ & V1 & 506 & $\mathrm{P} 1$ & V1 & 506 & $\mathrm{P} 1$ & V1 & 201 & 201 & 201 \\
\hline & \multirow{4}{*}{2} & & & 1250 & $\mathrm{P} 1$ & V1 & 1390 & $\mathrm{P} 1$ & $\mathrm{~V} 1$ & 907 & $\mathrm{P} 1$ & $\mathrm{~V} 1$ & 313 & 453 & 313 \\
\hline & & 1 & 937 & & & & & & & 343 & P2 & V4 & & & \\
\hline & & 2 & 140 & 550 & $\mathrm{P} 1$ & $\mathrm{~V} 1$ & - & P1 & V1 & 550 & $\mathrm{P} 1$ & V1 & 723 & 313 & 723 \\
\hline \multirow{7}{*}{4} & & 3 & 889 & 479 & $\mathrm{P} 1$ & V1 & 889 & $\mathrm{P} 1$ & V1 & 479 & $\mathrm{P} 1$ & V1 & 313 & 313 & 313 \\
\hline & \multirow[t]{2}{*}{1} & 1 & 301 & 580 & P2 & V4 & 674 & P2 & V4 & 761 & P2 & V4 & 279 & 373 & 460 \\
\hline & & 2 & 624 & 624 & $\mathrm{P} 1$ & V1 & 530 & $\mathrm{P} 1$ & V1 & 443 & $\mathrm{P} 1$ & $\mathrm{~V} 1$ & 279 & 279 & 279 \\
\hline & \multirow{5}{*}{2} & 3 & 835 & 835 & $\mathrm{P} 1$ & V1 & 835 & $\mathrm{P} 1$ & V2 & 835 & $\mathrm{P} 1$ & V1 & 279 & 279 & 279 \\
\hline & & & & 634 & P2 & V4 & 634 & P2 & V4 & 384 & $\mathrm{P} 1$ & $\mathrm{~V} 1$ & 300 & 300 & 619 \\
\hline & & 1 & 334 & & & & & & & 569 & $\mathrm{P} 2$ & $\mathrm{~V} 4$ & & & \\
\hline & & 2 & 861 & 861 & $\mathrm{P} 1$ & V1 & 1440 & $\mathrm{P} 1$ & $\mathrm{~V} 1$ & 542 & $\mathrm{P} 1$ & V1 & 300 & 879 & 300 \\
\hline \multirow{9}{*}{5} & & 3 & 899 & 899 & $\mathrm{P} 1$ & V1 & 320 & $\mathrm{P} 1$ & V2 & 899 & $\mathrm{P} 1$ & $\mathrm{~V} 1$ & 300 & 300 & 300 \\
\hline & \multirow{3}{*}{1} & 1 & 793 & 395 & $\mathrm{P} 1$ & V1 & 1119 & P2 & $\mathrm{V} 4$ & 1058 & P2 & $\mathrm{V} 4$ & 265 & 326 & 265 \\
\hline & & 1 & 793 & 663 & P2 & V4 & & & & & & & & & \\
\hline & & 2 & 315 & 315 & $\mathrm{P} 1$ & V1 & 254 & $\mathrm{P} 1$ & V1 & 315 & $\mathrm{P} 1$ & $\mathrm{~V} 1$ & 265 & 265 & 265 \\
\hline & \multirow{5}{*}{2} & 3 & 741 & 741 & $\mathrm{P} 1$ & V1 & 741 & $\mathrm{P} 1$ & V1 & 741 & $\mathrm{P} 1$ & $\mathrm{~V} 1$ & 265 & 265 & 265 \\
\hline & & & & 1341 & $\mathrm{P} 1$ & V1 & 863 & $\mathrm{P} 1$ & V1 & 641 & $\mathrm{P} 1$ & V1 & 712 & 283 & 283 \\
\hline & & 1 & 630 & 1 & P2 & $\mathrm{V} 4$ & 50 & $\mathrm{P} 2$ & $\mathrm{~V} 4$ & 272 & P2 & $\mathrm{V} 4$ & & & \\
\hline & & 2 & 496 & 670 & $\mathrm{P} 1$ & V1 & 496 & $\mathrm{P} 1$ & V1 & 496 & $\mathrm{P} 1$ & V1 & 886 & 283 & 283 \\
\hline & & 3 & 847 & 244 & $\mathrm{P} 1$ & $\mathrm{~V} 1$ & 847 & $\mathrm{P} 1$ & V1 & 847 & $\mathrm{P} 1$ & V1 & 283 & 283 & 283 \\
\hline
\end{tabular}

Pada iterasi ke-1, kapasitas waktu produksi dan kendaraan yang diinputkan pada model analitik sama dengan waktu tersedia yaitu sebesar 48 jam. Model analitik kemudian diselesaikan dengan menggunakan software LINGO 8.0. Solusi yang diperoleh pada iterasi 1 ditunjukkan pada Tabel 1 dan 2.
Solusi keputusan produksi pada iterasi ke-1 menunjukkan pabrik 2 hanya memproduksi produk 1 dan 2 pada periode ke-1 saja. Informasi lain pada Tabel 1 adalah kuantitas produksi di tiap pabrik, yang selanjutnya akan dikirim untuk memenuhi permintaan DC dan digunakan sebagai persediaan pabrik. Tabel 2 memberikan detail kuantitas pengiriman 
Tabel 3. Waktu simulasi dan selang kepercayaan rata-rata waktu simulasi pada iterasi ke-1

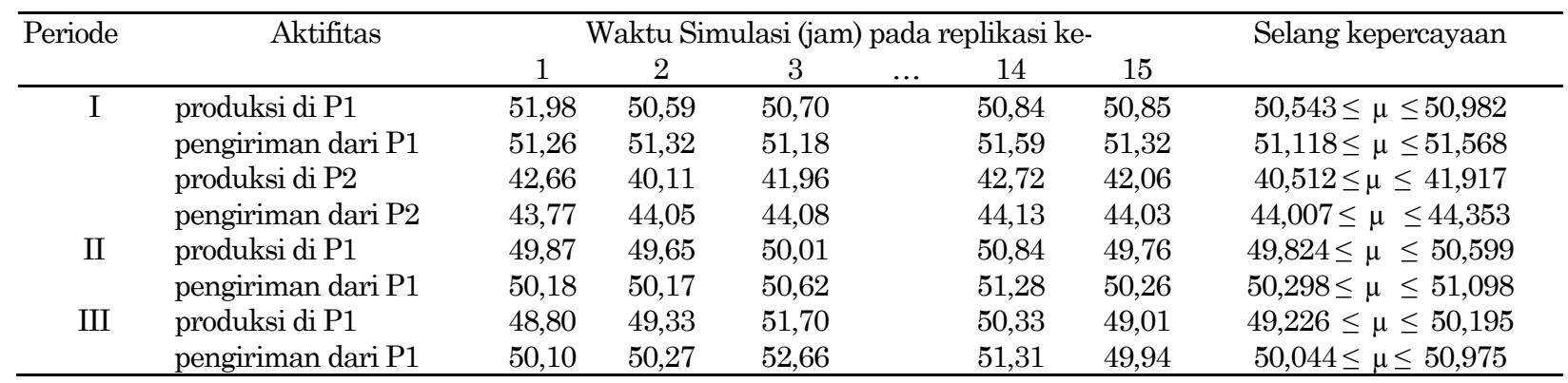

Tabel 4. Perhitungan CT, FP, dan ST berdasarkan prosedur hybrid analitik-simulasi

\begin{tabular}{|c|c|c|c|c|c|c|c|c|c|}
\hline \multirow{2}{*}{$\begin{array}{l}\text { Pabrik - } \\
\text { Periode }\end{array}$} & \multirow[t]{2}{*}{ Aktifitas } & \multicolumn{3}{|c|}{$\begin{array}{l}\text { Waktu Model Analitik pada } \\
\text { iterasi ke - }\end{array}$} & \multicolumn{2}{|c|}{$\begin{array}{l}\text { FP pada iterasi } \\
\text { ke - }\end{array}$} & \multicolumn{3}{|c|}{ Waktu Simulasi pada iterasi ke - } \\
\hline & & 1 & 2 & 3 & 1 & 2 & 1 & 2 & 3 \\
\hline \multirow{2}{*}{$\mathrm{P} 1$ - T1 } & Produksi & 48 & 45,19 & 42,54 & 0,941 & 0,941 & 50,98 & 48,011 & 45,53 \\
\hline & Pengiriman & 48 & 44,68 & 41,16 & 0,931 & 0,921 & 51,57 & 48,5 & 46,10 \\
\hline \multirow{2}{*}{$\mathrm{P} 2-\mathrm{T} 1$} & Produksi & 48 & 48 & 46,94 & - & 0,978 & 41,92 & 49,083 & 47,79 \\
\hline & Pengiriman & 48 & 48 & 43,52 & - & 0,907 & 44,35 & 52,942 & 47,96 \\
\hline \multirow{2}{*}{$\mathrm{P} 1$ - T2 } & Produksi & 48 & 45,53 & 43,19 & 0,948 & 0,948 & 50,60 & 48,010 & 46,46 \\
\hline & Pengiriman & 48 & 45,09 & 45,09 & 0,939 & 0,945 & 51,10 & 47,703 & 46,38 \\
\hline \multirow{2}{*}{$\mathrm{P} 2$ - T2 } & Produksi & 48 & 48 & 48 & - & - & - & - & - \\
\hline & Pengiriman & 48 & 48 & 48 & - & - & - & - & - \\
\hline \multirow[t]{2}{*}{ P1 - T3 } & Produksi & 48 & 45,90 & 43,43 & 0,956 & 0,946 & 50,19 & 48,511 & 43,08 \\
\hline & Pengiriman & 48 & 45,20 & 41,68 & 0,941 & 0,922 & 50,97 & 49,011 & 43,60 \\
\hline \multirow{2}{*}{ P2 - T3 } & Produksi & 48 & 48 & 48 & - & - & - & - & 13,29 \\
\hline & Pengiriman & 48 & 48 & 48 & - & - & - & - & 9,780 \\
\hline
\end{tabular}

dan jenis kendaraan yang digunakan dari tiap pabrik ke DC dan persediaan masing-masing DC tersebut pada iterasi 1. Sebagai contoh kuantitas pengiriman produk 1 dari Pabrik 2 ke DC 1 sebesar 963 pada periode 1 akan digunakan untuk memenuhi permintaan sebesar 491 dan persediaan sebesar 472.

Langkah berikutnya adalah running model simulasi dengan menggunakan software ARENA berdasarkan rencana produksi - distribusi pada iterasi ke-1 dan distribusi peluang dari faktor stokastik yang dipertimbangkan dalam penelitian ini yaitu waktu produksi, kecepatam kendaraan, waktu antar kerusakan mesin dan kendaraan, serta waktu perbaikan mesin dan kendaraan. Tabel 3 menunjukkan waktu simulasi untuk aktivitas produksi dan pengiriman dari hasil running model dengan replikasi sebanyak 15 kali.

Berdasarkan waktu simulasi pada tiap replikasi diperoleh selang kepercayaan rata-rata pada iterasi ke-1 ditunjukkan pada Tabel 3. Sesuai dengan prosedur yang dijelaskan pada Gambar 2 maka waktu simulasi (STPT) diambil dari batas atas selang kepercayaan tersebut, sehingga diperoleh waktu simulasi untuk melaksanakan produksi di pabrik 1 pada periode 1 sampai 3 sebesar 50,982, 50,599, dan 50,199 jam pada iterasi ke-1. Sedangkan waktu simulasi di pabrik 2 pada periode 2 dan 3 sama dengan nol karena tidak ada produksi pada periode tersebut.

Dengan membandingkan waktu simulasi dan waktu aktual yang tersedia diperoleh kesimpulan solusi model analitik pada iterasi ke-1 tidak layak diimplementasikan karena waktu aktual yang dibutuhkan pabrik 1 untuk memproduksi dan mengirimkan produk ke semua DC melebihi 48 jam pada periode 1 sampai 3. Selanjutnya berdasarkan prosedur pada gambar 2, dilakukan perhitungan faktor penyesuaian dan kapasitas waktu yang akan diinputkan ke model analitik pada iterasi ke-2. Dengan menggunakan persamaan 15 dan 16 diperoleh faktor penyesuaian dan kapasitas waktu produksi yang diinputkan pada model analitik untuk iterasi ke-2 di pabrik 1 adalah:

$$
\begin{aligned}
& F P_{1}=\frac{C T_{11}(1)}{S T_{11}(1)}=\frac{48}{50,982}=0,941 \\
& C T_{11}(2)=C T_{11}(1) \times F P_{1}=48 \times 0,9415=45,19
\end{aligned}
$$

Waktu simulasi untuk aktifitas produksi dan pengiriman di pabrik 2 pada iterasi ke-1 tidak melebihi 48 jam pada periode 1-3 seperti ditunjukkan pada Tabel 4. Berdasarkan waktu simulasi tersebut maka tidak perlu dilakukan perhitungan faktor penyesuaian dan kapasitas waktu yang diinputkan ke model analitik pada iterasi ke-2 tetap sebesar 48 jam. 
Hasil perhitungan kapasitas yang baru selanjutnya digunakan untuk megubah nilai right hand side pada persamaan 1 dan 11 dan model analitik dirunning kembali sehingga diperoleh solusi model analitik pada iterasi ke-2 seperti ditunjukkan pada Tabel 1 dan 2 . Hasil penyesuaian kapasitas tersebut menyebabkan jumlah produksi di pabrik 1 cenderung lebih sedikit dibanding iterasi ke-1 agar waktu simulasi yang dibutuhkan untuk produksi di pabrik 1 menjadi realistis yaitu mendekati 48 jam dan sebaliknya jumlah produksi di pabrik 2 meningkat agar permintaan DC tetap terpenuhi.

Proses dilanjutkan dengan mengikuti langkah-langkah pada Gambar 2, sehingga diperoleh kapasitas waktu yang diinputkan pada model analitik, hasil perhitungan faktor penyesuaian dan waktu simulasi pada tiap iterasi ditunjukkan pada Tabel 4. Hasil running model simulasi pada iterasi ke-3 menunjukkan waktu yang dibutuhkan untuk menjalankan rencana produksi dan pengiriman di pabrik 1 dan 2 tidak ada yang melebihi waktu 48 jam pada periode 1 sampai 3. Sesuai dengan prosedur hybrid analitiksimulasi yang telah dikembangkan maka iterasi dihentikan dan solusi rencana produksi-distribusi yang optimal dan layak telah diperoleh.

Tabel 1 menunjukkan solusi model analitik pada iterasi ke-3 cukup berbeda dengan iterasi ke-1 terkait dengan keputusan pabrik yang melakukan produksi dan jumlah produksinya. Pada iterasi ke-3, kapasitas waktu produksi pada pabrik 1 yang diinputkan ke model analitik menjadi sekitar 43 jam (seperti ditunjukkan pada Tabel 4). Sehingga pabrik 2 juga harus melakukan produksi pada periode ke-3 agar permintaan seluruh DC tetap terpenuhi meskipun biaya produksi dan simpan untuk membuat produk 1 dan 2 lebih mahal pada pabrik 2. Peningkatan total biaya untuk menjalankan rencana produksi-distribusi pada iterasi ke-3 harus dilakukan agar solusi dari model analitik layak diimplementasikan karena mempertimbangkan berbagai faktor stokastik yang terjadi pada supply chain. Dengan mengkombinasikan kemampuan model analitik dalam mendapatkan solusi optimal dan kemampuan model simulasi dalam mengakomodasi faktor stokastik maka rencana produksi-distribusi menjadi lebih real untuk diimplementasikan pada sebuah supply chain.

\section{Simpulan}

Berdasarkan penyelesaian problem integrasi produksidistribusi dengan pendekatan yang diusulkan, dapat disimpulkan solusi awal model analitik tidak dapat diimplementasikan di realita yang memiliki karakteristik stokastik. Oleh karena itu penyesuaian kapasitas berdasarkan waktu simulasi diguna- kan untuk megubah nilai sisi kanan pada pembatas kapasitas waktu produksi di pabrik dan kapasitas waktu yang dimiliki tiap kendaraan pada model analitik. Hasil dari penyesuaian kapasitas secara signifikan mempengaruhi rencana produksi-distribusi. Konsekuensi yang harus ditanggung supply chain dengan implementasi pendekatan hybrid analitik-simulasi adalah penambahan biaya setup pabrik, produksi pada pabrik dengan biaya produksi, simpan dan pengiriman yang lebih mahal, serta biaya kesempatan yang hilang untuk memenuhi permintaan langsung konsumen. Namun dengan menggunakan keunggulan dari kedua model tersebut maka pencarian solusi akan mempertimbangkan struktur biaya yang harus dikeluarkan dan faktor stokastik yang terjadi pada supply chain sehingga solusi yang diperoleh mendekati optimal dan layak untuk diimplementasikan di realita.

Penelitian lanjutan yang bisa dilakukan untuk menyempurnakan yang ada saat ini adalah: Mengembangkan model simulasi dengan menggunakan module-based modeling sehingga waktu yang dibutuhkan untuk membangun sistem supply chain yang kompleks menjadi lebih singkat dan memiliki fleksibilitas yang tinggi dengan adanya perubahan konfigurasi sistem. Merancang agar output model simulasi di-generate secara otomatis dan disimpan dalam bentuk file Excel sehingga mempercepat penyesuaian kapasitas pada model analitiknya. Memasukkan biaya-biaya yang diperlukan untuk melakukan penyesuaian kapasitas.

\section{Ucapan Terima Kasih}

Peneliti mengucapkan terima kasih kepada para Reviewer yang telah banyak memberikan masukan untuk perbaikan paper ini.

\section{Daftar Pustaka}

1. Alfieri, A., and P. Brandimarte, Object Oriented Modelling and Simulation of Integrated Production Distribution System. Computer Integrated Manufacturing Systems, 10(4), 1997, pp. 261-266.

2. Chairunisah, Model Program Stokastik dalam Transportasi dan Logistik. Thesis, Program Studi Magister Matematika, Universitas Sumatera Utara, 2009.

3. Chen, Z. L., Integrated Production and Distribution Operations: Taxonomy, Models, Review. in Handbook of Quantitative Supply chain Analysis: Modelling in the E-Business Era, Kluwer Academic Publishers, 2004.

4. Fahimnia, B., Lee L., and Romeo M., Optimization/Simulation Modeling of The Integrated Production-Distribution Plan: An Innovative 
Survey. WSEAS Transactions on Business and Economics, 3(5), 2008, pp. 44-57.

5. Garside, A. K., A Simulation Model for Integrated Production - Distribution Problem. International Seminar On Industrial Engineering and Management, Bali-Indonesia, 2009, pp. 22-34.

6. Garside, A. K., Model Simultan dan Decoupled untuk Penyelesaian Problem Integrasi Produksi - Persediaan - Distribusi - Persediaan. Jurnal Teknik Industri, 10(1), 2008, pp. 11-25.

7. Lee, Y. H., and Sook, H. K., Optimal Production - Distribution Planning in Supply Chain Management Using a Hybrid Simulation - Analytic Approach. Proceedings of the 2000 Winter Simulation Conference, 2000, pp. 1252-1259.

8. Lim, S. J., Suk J. J., Kyung S. K., and Myon W. P., A Simulation Approach for Production-Distribution Planning with Consideration Given to
Replenishment Policies. The International Journal of Advanced Manufaturing Technology, 27(5), 2006, pp. 593-603.

9. Sumarwan, U., Dadang S., Ali K., dan Yekti H.E., Model Perencanaan Konsumsi pangan yang Memenuhi Kebutuhan Gizi, Kebiasaan Pangan dengan Biaya Minimum (Studi Kasus di Desa Cibitung Kulon, Kecamatan Pamijahan, Kabupaten Bogor, Jawa Barat). Media Gizi dan Keluarga, XXI (2), 1997, pp. 17-27.

10. Thomas, D. J., and Paul M. G., Coordinated Supply Chain Management. European Journal of Operational Research, 94, 1996, pp. 1-15.

11. Wang X., and Soemon T., Moduled - Based Modelling of Production-Distribution Systems Considering Shipment Consolidation. Proceedings of the 2006 Winter Simulation Conference, 2006, pp. 1477-1484. 